\title{
Formación jurídica y androcentrismo
}

\author{
Legal training and androcentrism
}

Malena Costa Wegsman*

Recepción: 18/07/2017

Aceptación: 10/10/2017

Recepción y aceptación final: 31/05/2018

\begin{abstract}
Resumen: Asistimos desde hace décadas a una acelerada sucesión de cambios que ponen en jaque los tradicionales esquemas de comprensión de la política, la economía y la sociología. Es en ese marco que se sitúa el texto de la Profesora Josefa Ruiz Resa, "La enseñanza del Derecho en la economía del aprendizaje", analizado a continuación. La lectura del texto que se presenta se articula con la introducción de una discusión ausente aunque insoslayable para pensar el escenario sociopolítico donde se enmarcan las tendencias de las profesiones jurídicas en la actualidad. Al asumir el androcentrismo constitutivo del campo jurídico, los efectos de ese condicionamiento resultan impostergables para cualquier análisis de las profesiones del Derecho. A partir de un acuerdo básico con la hipótesis de trabajo de la Profesora, se proponen claves para comprender la recurrencia de la lógica androcéntrica en el escenario actual de la enseñanza del Derecho y las profesiones jurídicas.
\end{abstract}

Palabras clave: Androcentrismo, Derecho, academia

* Profesora en Filosofía y Doctora de la Universidad de Buenos Aires con mención en Estudios de Género. Instituto Interdisciplinario de Estudios de Género, Facultad de Filosofía y Letras, Universidad de Buenos Aires/Consejo Nacional de Investigaciones Científicas y Técnicas, Ministerio de Ciencia y Tecnología de la Nación, Ciudad Autónoma de Buenos Aires, República Argentina, malenacostaw@gmail.com 
Malena Costa Wegsman

\begin{abstract}
We have been witnessing, for decades, an accelerated succession of changes that put in check the traditional schemes of understanding of politics, economy and society. The article analyzed below "The teaching of Law in the economy of learning", by Professor Josefa Ruiz Resa, it is placed within that framework. The reading of the text presented is articulated with the introduction of an absent but inescapable discussion to think about the sociopolitical scenario where the trends of the legal professions are framed today. By assuming the constitutive androcentric of the legal field, the effects of this conditioning can not be postponed for any analysis of the legal professions. Based on a basic agreement with the hypothesis of the Professor's work, keys are proposed to understand the recurrence of androcentric logic in the current scenario of legal education and the legal professions.
\end{abstract}

Keywords: Androcentrism, Law, academy.

\title{
I. Introducción
}

A lo largo de los últimos años y desde diversos enfoques disciplinares, los estudios críticos se desvelan por dar cuenta de las profundas transformaciones que acontecen en todos los órdenes de la vida. La legitimidad y los límites de la representación política, la cada vez más evidente porosidad de las fronteras nacionales, el recrudecimiento del capital financiero, las novedosas formas de agresión masiva englobadas bajo el rótulo de terrorismo. Asistimos desde hace décadas a una acelerada sucesión de cambios y movimientos que ponen en jaque los tradicionales esquemas de comprensión de la política, la economía y la sociología.

En efecto, el fin del milenio encuentra a las disciplinas sociales y a las humanidades envueltas en lo que se denomina "crisis de la Modernidad". Entre los reparos que se imponen sobre los alcances del saber y el hacer científico y la noción de progreso -reparos que se recrudecen, de manera inevitable, tras la Segunda Guerra Mundial-, y con el incierto pero no menos contundente acervo de ideas llamadas postmodernas, la inteligibilidad Moderna es confrontada a una serie de conflictos que socavan la solidez de sus cimientos. Las epistemologías basadas en un sujeto autoconsciente, la validación del conocimiento a 
través una razón universal, los límites del Estado-nación, en fin, cada uno de los elementos pilares de la Modernidad son sometidos a discusión, mientras los ecos de las políticas de exterminio resuenan en una advertencia tan inevitable como recurrente, con la incesante propagación de conflictos bélicos articulados sobre tecnologías cada vez más sofisticadas.

Las posibilidades de que la razón sea argumento para el horror, la omnipresencia transnacionalizada de las potencias financieras, la consolidación de grupos neofascistas, el quiebre aparentemente definitivo de los regímenes socialistas se entrecruzan con reivindicaciones identitarias cada vez más variadas, alianzas emergentes en la acción directa con el veloz impulso y la amplificación inusitada de las tecnologías de la información y la comunicación, y un incremento inconmensurable, en cantidad y variedad, de masas de personas que se ven en la situación de abandonar su lugar de origen, en busca de mejores condiciones de vida o, simplemente, de una mínima y básica garantía de poder continuar con vida. Es en medio de esta vehemencia crítica, y con una sombra de incertidumbre como telón de fondo epistemológico y político, que se erige la inquietud respecto de las posibilidades y los condicionamientos de los saberes académicos. Es ese el marco en el que se sitúa el texto de la Profesora Josefa Ruiz Resa, "La enseñanza del Derecho en la economía del aprendizaje" analizado a continuación.

La lectura del texto que se propone a continuación se articula a partir de la introducción de una discusión ausente y que, no obstante, resulta insoslayable para pensar el escenario sociopolítico donde se enmarcan las tendencias y las posibilidades de las profesiones jurídicas en la actualidad. Al asumir el androcentrismo constitutivo del campo jurídico, los efectos de ese condicionamiento resultan impostergables para cualquier análisis de las profesiones del Derecho. Así, a partir de un acuerdo básico con la hipótesis de trabajo de la Profesora, se proponen claves para comprender la persistente recurrencia de la lógica androcéntrica en el escenario sociopolítico-económico actual, respecto de la enseñanza del Derecho y las profesiones jurídicas. Estas claves de comprensión se sustentan sobre los postulados feministas en el campo jurídico, en las variadas intervenciones de este movimiento en la ense- 
ñanza del Derecho y en los estudios feministas sobre la situación actual de las identificaciones femeninas - principalmente mujeres, pero también lesbianas y trans- en la academia legal. Hacia el final se presentan algunos elementos de las genealogías y las intervenciones de los feminismos jurídicos en la academia, a fin de sugerir posibles modalidades de acción para confrontar las implicancias del escenario sociopolítico contemporáneo sobre la enseñanza del Derecho y la construcción del campo jurídico en general.

\section{Economía del aprendizaje}

En "La enseñanza del Derecho...", Josefa Ruiz Resa afirma que la fase actual del capitalismo globalizado se caracteriza por la organización de comunidades políticas comandadas desde los intereses de grandes empresas multinacionales, y, por lo tanto, con una sostenida profundización de las desigualdades socioeconómicas y una tendiente contracción de la legalidad estatal. A esta fase, denominada economía del aprendizaje, le corresponde asimismo un modelo profesional específico, sustentado en un paradigma técnico-económico. Bajo este paradigma, el conocimiento se institucionaliza en tanto producto de la transformación de la información, y, de esa manera, se vuelve particularmente susceptible de mercantilización. La noción de economía del aprendizaje alude así a una modalidad socioeconómica que resulta de la primacía de un modelo de producción vinculado con dicha concepción mercantilizante del conocimiento, en la que las creaciones e innovaciones se consideran en términos de tecnologías, sociales o físicas. Las profesiones de los distintos campos del conocimiento se estructuran a partir de los postulados de esta fase del capitalismo y mediante las lógicas de ese paradigma, procurando ajustarse a los requerimientos de empleabilidad, en la exigencia de aptitudes individuales, habilidades creativas y en el acopio de competencias siempre renovadas, con el objetivo de potenciar el valor de la mercancía ofertada. 
Es así que Ruiz Resa califica como "pegajoso"1 a este modo de conocimiento en la formación profesional, ajustado a las exigencias del mercado y mandatario de una actualización constante.

En relación con las profesiones jurídicas, las transformaciones de la economía del aprendizaje se advierten, entre otros aspectos, en la incorporación de las escuelas del Derecho a los sistemas nacionales de investigación científica, y en la orientación de la transferencia del conocimiento hacia los fines e intereses de las grandes empresas, orientación que es acompañada, en muchas ocasiones, de la adaptación de las Facultades al funcionamiento empresarial. En línea con la actual fase de la economía política global, las profesiones jurídicas se estructuran para servir, desde distintos estratos y con diferentes grados de relación y modos de complicidad, a esas empresas en las que se aglomeran quienes ostentan la mayor acumulación de riqueza a nivel mundial. Como contraparte, la planificación de la formación para las profesiones jurídicas no contempla a las grandes mayorías, es decir, ni a los sectores asalariados ni a los altamente empobrecidos, quienes quedan, de este modo, en la intemperie de unos dispositivos jurídicos cada vez más desguazados y determinados por racionalidades vinculadas con las doctrinas de la seguridad y el orden.

A partir de estas agudas observaciones, la Profesora Ruiz Resa califica al escenario actual como "desasosegante" ${ }^{\text {. Desde un total }}$ acuerdo con esta apreciación, se advierte, no obstante, la ineludible necesidad de profundizar este análisis desde una lectura feminista, considerando las desiguales consecuencias sexogenéricas que la economía del aprendizaje apareja en lo concerniente a las profesiones jurídicas y en la vinculación con el campo jurídico en su conjunto. Para ello, a continuación se ofrecen algunos comentarios sobre ciertos puntos del análisis de la Profesora Ruiz Resa, con la intención de que resulten útiles para enriquecer la lectura.

1 Ver punto I.2 "El paradigma tecno-político" en Ruiz Resa, J., "La enseñanza del derecho en la economía del aprendizaje", Revista Discusiones, en este número.

2 Ídem. 


\section{La ambigüedad igualitaria}

En la advertencia del desasosiego que genera la actual fase del capitalismo, Josefa Ruiz Resa llama a analizar el escenario de la formación jurídica desde un enfoque más amplio, considerando "la discusión sobre la comunidad política y jurídica en que se ejercen las profesiones jurídicas y se enseña el derecho"3. De ese modo es posible advertir los efectos que las actuales exigencias del conocimiento jurídico y sus condicionamientos en términos mercantiles suponen "para amplias capas de población, cada vez más empobrecidas" ", sobre todo, por cuanto que el contrato se impone como modalidad jurídica más extendida, con las consecuentes limitaciones para quienes no cuentan con conocimientos, patrocinio o asesoramiento legal, y también en lo referente al acceso a la justicia. Así, Ruiz Resa advierte que las profesiones jurídicas carecen hoy "de la formación humanística que se reclamaba en otras épocas, como en la Ilustración" 5 . En tal sentido, resulta oportuno reponer los presupuestos que sustentaron la tradición jurídica humanística, en esa puja de movimientos contradictorios que constituyó la Ilustración.

Las transformaciones que se abren paso a través de las revoluciones modernas y las ideas ilustradas están sustentadas en conceptos ambiguos. Para muchas y para muchos, la igualdad moderna repercute en crudas paradojas, mientras que el nuevo orden moderno ofrece límites no tan novedosos. Las promesas de emancipación y progreso que abundan en las proclamas de las revoluciones burguesas, con su entusiasmo pujante por los radicales cambios de la Modernidad, trazan las narraciones de los nuevos discursos de la política y la ciencia. Estos quiebres políticos revolucionarios responden también a transformaciones epistemológicas que replantean la ontología del orden establecido: en un inusitado proceso de individuación, el sujeto moderno se erige en tanto ser independiente del mundo que habita. El antiguo régimen da

3 Ver punto V “Conclusiones” en Ruiz Resa, J., "La enseñanza del derecho en la economía del aprendizaje”, op. cit.

4 Ídem. 
paso a la proliferación de individuos libres, iguales entre sí en función de su vinculación con la ley. Así, la igualdad es el principio que rige la relación del nuevo orden político en un mundo desencantado. Ante el imperio de la ley, frente a la autoridad del Estado, todos los hombres son iguales. La noción de igualdad se instituye así como un componente básico del pensamiento político moderno. En tanto ideal de la Ilustración, la igualdad se erige en las mentes modernas como el eje regulador de la vida en una sociedad de individuos libres. Se trata de una transformación radical respecto de los criterios de organización previos.

Con todo, la universalidad de la igualdad moderna se formula en simultáneo con la restitución velada de unas condiciones sociales que se suponen proscriptas en las nuevas formas de la política. Karl Marx desentraña con implacable lucidez los términos de esta contradicción. Marx afirma que la consumación de la igualdad moderna, la igualdad en términos de ciudadanía, se asienta sobre la abstracción de las desigualdades materiales que operan en la sociedad. La igualdad moderna, por lo tanto, se sustenta en el desdoblamiento entre una esfera de igualdad jurídica, en la que los ciudadanos son iguales en términos políticos, y la esfera social, en la que los individuos se relacionan mediante las desiguales formas del capitalismo. Las diferencias "de nacimiento, estado social, de cultura y de ocupación"6 son anuladas por el Estado al asumir a cada hombre como ciudadano. Dicha abstracción encuentra en los preceptos del iusnaturalismo su fuente de legitimidad filosófica. Tal como lo reseña Joan Scott, "Para los teóricos políticos de la época de la Revolución francesa, el individuo abstracto expresaba esa esencia común a toda la humanidad. Sus derechos eran considerados naturales" 7 . El sujeto del Derecho moderno se establece así sobre la concepción de una individualidad abstracta y neutral. Sin embargo, según lo advierte Marx, a pesar de la proclamación de la igualdad en la esfera política de la ciudadanía, las desigualdades de la vida en la sociedad civil perduran en su concreta materialidad, de

6 Marx, K., Sobre la cuestión judía, Buenos Aires, CS Ediciones, 1999, pág. 27.

7 Scott, J. W., Las mujeres y los derechos del hombre: feminismo y sufragio en Francia, 17891944, Buenos Aires, Siglo Veintiuno Editores, 2002, pág. 23. 
modo que la igualdad de los ciudadanos ante la ley se encuentra "por oposición a su vida material"8.

Aun así, la transformación que implica la igualdad moderna es decisiva. Asentada sobre la ambivalencia de una universalidad restringida, la igualdad configura el punto de fuga por el cual desestabilizar el nuevo orden a través del cuestionamiento de las jerarquías y las subalternaciones que lo conforman. En tal sentido, para comprender la vigencia de las contradicciones jurídicas, presentes también en la configuración de los actuales perfiles profesionales, es necesario adentrarse en los modos específicos de subalternación resultantes de la paradójica universalidad igualitaria, eje de la política y el derecho modernos.

\section{Humano, demasiado humano}

Tal como lo afirma Marx, la igualdad moderna no solo es un ideal, sino que es, por definición, ideal, en la medida en que regula los conflictos de una ciudadanía abstracta y a su vez niega las contradicciones de la vida material de los individuos en la sociedad civil. Los ciudadanos son iguales en tanto seres abstractos.

No obstante, en sus análisis de la igualdad burguesa, la abstracción de las condiciones materiales y las desigualdades sociales, Marx omite ciertas materialidades que exceden la gramática de la lucha de clases. En efecto, la postulación del Hombre como sujeto del Derecho implica la legitimación de una determinada humanidad, la conformación de un modelo de lo humano que es el que se corresponde con ese universal ciudadano. La igualdad, en tanto ideal social y principio normativo regulado jurídicamente, delimita, elípticamente, un universo humano. Desde el pensamiento feminista se advierte que tanto el establecimiento del varón como universal de lo humano, así como la subalternación de las mujeres y todas las identificaciones sexodisidentes en las formulaciones jurídicas, responden a la condición inherentemente androcéntrica del Derecho. El androcentrismo jurídico se evidencia en 
la funcionalidad del Derecho para consolidar el privilegio de un sujeto postulado como neutral pero concebido en los términos del Hombre y el Ciudadano, es decir, en la legitimación de una humanidad proclamada en su igualdad universal pero delimitada en su particular condición masculina. Como lo afirma Lipszyc, "Los 'iguales' fueron los que pudieron asimilar el modelo 'humano' impuesto por la burguesía triunfante. Ese modelo fue el del varón blanco, instruido, propietario y heterosexual"9.

En la delimitación del universo de lo humano, la razón tiene un papel preponderante. En efecto, la igualdad jurídica se formula como un principio normativo para regular la vida en sociedad de los ciudadanos, hombres libres. El universo de los individuos iguales se restringe entre quienes comparten la cualidad de seres libres en función de su autonomía. La autonomía, a su vez, se determina en virtud de una particular concepción de la capacidad de razón. Por fin, la definición del individuo libre y autónomo que encarna el sujeto del derecho moderno se corresponde con quienes detentan la capacidad de razón, esto es, el conjunto de los varones blancos, adultos y propietarios. La razón, pilar del movimiento ilustrado, núcleo de la autonomía, motor del progreso y de los discursos científicos, es el eje de las transformaciones que dan curso a la individuación, a la concepción de una libertad que implica la ruptura con la autoridad heterónoma. En simultáneo, la razón opera como artilugio discursivo para la des-calificación de quienes no acreditan los atributos que definen al hombre y al ciudadano. El ciudadano constituye la legitimación legal del modelo de individuo racional, es decir, del hombre adulto blanco heterosexual capaz y propietario como modelo de lo humano. En ese sentido, no es sorprendente que quienes se apartan de ese modelo de humanidad conformen los grupos que ejercen la titularidad de los derechos específicos: las mujeres, lesbianas, trans e intersex, las niñas y los niños, los sujetos racializados, las personas con discapacidad, las refugiadas. En esa línea también se comprende la relevancia de esclarecer que los derechos humanos de la

9 Lipszyc, C., "Ciudadanía”, en Gamba, S. (ed.), Diccionario de estudios de género y feminismos, Buenos Aires, Biblos, 2007, pág. 59. 
mujer y de la niña son parte inalienable, integrante e indivisible de los derechos humanos universales, tal como se afirma en la Declaración de la Conferencia Mundial de Derechos Humanos, propiciada por la Organización de las Naciones Unidas y celebrada en Viena en 1993.

\section{La racionalidad jurídica moderna}

Respecto del modelo de comunidad política dominante en la economía del aprendizaje, la Prof. Ruiz Resa afirma que es "desigualitario y tiránico, aparentemente individualista pero en cuyo fondo subyace el poder de grandes empresas", y advierte también que este modelo "tiene como fuente jurídica principal el contrato entre individuos y grupos con desigual poder de negociación" ${ }^{10}$. En este sentido, desde el pensamiento feminista se ha señalado al contrato como un dispositivo clave del androcentrismo jurídico, en la medida en que se presenta como un mecanismo de negociación neutralizado, pasible de ser celebrado en condiciones de igualdad y libertad. Por consiguiente, considerando la subalternación jurídica del amplísimo y variado conjunto de quienes no se corresponden con el sujeto del Derecho androcéntrico, el contrato constituye la puesta en escena de la contradicción moderna, en la postulación universal de una igualdad demarcada sobre un conjunto particular y específico en su masculinidad normativa.

En su crítica feminista al liberalismo político, Carole Pateman afirma que "El contrato siempre genera el derecho político en forma de relaciones de dominación y de subordinación" ${ }^{11}$. Pateman retoma las ideas centrales del contractualismo moderno para mostrar cómo el potencial igualitario de esta tradición termina por negar y así legitimar la subordinación de las mujeres. En tal sentido, sostiene que "(...) los capitalistas pueden explotar a los trabajadores y los esposos

${ }^{10}$ Ver punto I "Introducción” en Ruiz Resa, J., op. cit.

11 Pateman, C., El contrato sexual, Barcelona, Anthropos, 1995, pág. 18. 
a las esposas porque los trabajadores y las esposas se constituyen en subordinados a través del contrato de empleo y del de matrimonio"12.

El argumento de Pateman es que la teoría política moderna se apoya sobre la ficción de la figura del contrato y opera mediante una proyección del estado de naturaleza hacia el ámbito privado para legitimar, en simultáneo, la libertad civil de los varones y la sujeción de las mujeres. Esta sujeción que se establece en términos contractuales es, en consecuencia, regulada a través del Derecho. En ese sentido, Pateman también alude a la razón en tanto artilugio jurídico para la subalternación femenina. En efecto, Pateman sostiene que la subalternidad jurídica de las mujeres se sustenta en una particular concepción de naturaleza femenina, formulada por la tradición contractualista para abonar a una supuesta debilidad e irracionalidad constitutiva de las mujeres. Es esa particular naturaleza la que, en definitiva, las separa como un conjunto específico dentro de la generalidad de lo humano y las distingue radicalmente de la figura del individuo y ciudadano moderno. Así, tal como lo advierte Pateman, "sólo los seres masculinos están dotados de los atributos y las capacidades necesarias para realizar un contrato" 13 .

La pensadora del contractualismo se apoya en este punto en uno de los más contundentes postulados de los feminismos, elaborado por Simone de Beauvoir en su profuso ensayo El Segundo Sexo ${ }^{14}$. Allí de Beauvoir afirma que on ne naît pas femme, on le devient, "no se nace mujer, se llega a serlo", afirmación cuyos efectos filosóficos y políticos resultan inconmensurables. Para de Beauvoir, la condición subalterna, que hace de la diferencia una cualidad específica de las mujeres, es la contracara necesaria para erigir la centralidad de lo masculino. En esa línea argumentativa, de Beauvoir destaca el concepto de racionalidad como un instrumento central para el ejercicio del poder masculino. La razón, como patrimonio de la normatividad masculina, coloca a las mujeres en una situación de inferioridad y dependencia frente a los

\footnotetext{
12 Ídem.

${ }^{13}$ Ibidem., pp. 14-15.

${ }^{14}$ De Beauvoir, S., El segundo sexo, Buenos Aires, Sudamericana, 2007.
} 
varones, a la vez que justifica este orden de alteridad al signarlas como irracionales, caóticas, compulsivas, intuitivas, deficientes y/o peligrosas. Pateman advierte que la subordinación femenina justificada a través de la adjudicación de una naturaleza particular permanece como lo reprimido en el inconsciente contractualista. Con ese argumento se sustenta la exclusión de las mujeres en la participación del contrato, no obstante lo cual estas abandonan el estado de naturaleza, aunque su destino es una extraña zona ambigua que forma parte de la sociedad civil y a la vez se distingue de esta. Esa zona es la esfera doméstica, que delimita espacialmente el punto originario de la ciudadanía trunca de las mujeres puesto que se trata de un ámbito que permanece exento de regulación legal ${ }^{15}$ y también carente de incumbencia para las investigaciones de las disciplinas científicas ${ }^{16}$.

Si bien el punto de partida para la organización del movimiento feminista es la particular condición subalterna de las mujeres, particular por su persistencia y por su amplitud, también es cierto que el accionar político de los feminismos está abocado sobre esa condición en un afán de comprenderla y desarticularla. En función de tal ambiciosa empresa, Pateman no puede dejar de advertir que el contrato encierra la subordinación no sólo de las mujeres en general sino también de todas aquellas personas que no se correspondan con un modelo específico de la masculinidad: "Los varones que (se dice que) hacen el contrato original son blancos, y su pacto fraternal tiene tres aspectos: el contrato social, el contrato sexual y el contrato de esclavitud que legitima el gobierno del blanco sobre el negro"17.

15 Olsen, F., "Feminism and Critical Legal Theory: An American Perspective", en Olsen, F. (ed.), Feminist Legal Theory I: Foundations and Outlooks, New York, New York University Press, 1995, pp. 473-485.

16 Smith, D. "Women's Perspective as Radical Critique of Sociology", en Fox Keller, E. y Longino, H. (eds.), Feminism \& Science, Oxford, Oxford University Press, 1996, pp. 27-38.

17 Pateman, C., op. cit., pág. 302. 


\section{La neutralidad androcéntrica}

En su crítica al liberalismo moderno, Pateman desentraña la manera en la que la ficción del contrato se articula con un ideal de la razón. La razón moderna, con sus pretensiones de neutralidad objetiva, es señalada desde los feminismos como un artilugio para la subalternación de quienes se apartan de la normatividad masculina. Como advirtiera de Beauvoir, la razón es el pilar del "uno" masculino sobre el que se establecen y definen las contracaras de lo otro. Los presupuestos del derecho moderno también se erigen en esa concepción de racionalidad. En tal sentido, el acceso a la justicia, menoscabado, tal como lo advierte la Prof. Ruiz Resa, para los sectores más empobrecidos, se ve particularmente restringido para las mujeres, lesbianas y trans y, en general, para todos los grupos de las sexualidades disidentes. En efecto, los sistemas jurídicos y las instituciones judiciales, fundados, presuntamente, en la abstracción y la neutralidad, responden -aun hoy- a una persistente cosmovisión androcéntrica. Así, la vigencia del androcentrismo en la institucionalidad jurídica es señalada como uno de los principales motivos para el impedimento o la dificultad en el acceso a la justicia para las feminidades ${ }^{18} \mathrm{y}$, particularmente, para las personas intersex.

Desde el pensamiento feminista se asume la contingencia de las características que definen a las identificaciones sexogenéricas (como la noción de naturaleza femenina, mencionada arriba), y asimismo se cuestiona tanto la primacía de la normatividad masculina como, en términos más amplios, el binarismo sexual. De este modo, una de las más destacables intervenciones feministas en el campo jurídico refiere a la indagación y a la discusión sobre los modos en los que el Derecho opera en relación con las jerarquizaciones sexuales. Así, un manto de sospecha se imprime sobre las posibilidades de la neutralidad del discurso jurídico. En efecto, el cuestionamiento sobre la neutralidad del Derecho es uno de los postulados generales de los feminismos jurídcos. A partir de esa premisa principal, es posible advertir, por ejemplo,

${ }^{18}$ Heim, D., Mujeres y acceso a la justicia, Buenos Aires, Didot, 2016. 
cómo la normativa jurídica produce sentidos sexogenéricos, aunque presentados como una lectura directa e imparcial de los hechos y, en definitiva, como características de las diferencias sexuales naturales. La natural debilidad e irracionalidad femenina, argumentada en función de privar a las mujeres del ejercicio de los derechos políticos, es un claro ejemplo de ello. Desde el pensamiento feminista se advierte que la pretendida neutralidad del discurso del Derecho se postula en función de ocultar o velar su carácter productivo ${ }^{19}$. De este modo, por ejemplo, las figuras legales a través de las que se define a los sujetos aparecen naturalizadas, como consecuencia de una presunta lectura objetiva de la naturaleza misma ${ }^{20}$.

La impugnación feminista a la neutralidad jurídica conlleva un cambio en la concepción de los factores que intervienen en la construcción del Derecho. Se trata de un cuestionamiento amparado en una transformación más amplia, efecto de la redefinición de los alcances de la política, de lo político y, desde ya, de la regulación legal. La advertencia de que la condición subalterna de las mujeres se produce en primera instancia en el espacio doméstico, ámbito de lo privado (advertencia que magistralmente plasmara Simone de Beauvoir en $E l$ Segundo Sexo), promueve la necesidad de repensar los alcances de la regulación jurídico-política. Así, desde la década de 1970, la consigna feminista "lo personal es político" conmueve los presupuestos de la política y del Derecho. En primer lugar, porque con esa afirmación se amplía el terreno de lo político, traspasando el plano de las instituciones públicas. En segundo lugar, puesto que se trata de una advertencia epistemológica, en la medida en que se plantea la interdependencia de dos planos, el público y el privado, que las tradiciones del pensamiento político y jurídico consideran separados. Con esta afirmación, en cambio, se postula la vinculación indisociable entre esos ámbitos. La redefinición de lo político lleva a las discusiones feministas a cen-

${ }^{19}$ Costa Wegsman, M., "Introducción al dossier: Pensando El Derecho en Clave Pro-Fémina”, Revista Electrónica. Instituto de Investigaciones Ambrosio L. Gioja, 19, 2017, pp. 2-11.

${ }^{20}$ Frug, M. J., "A postmodern legal manifesto", en Olsen, F., Feminist Legal Theory I: Foundations and Outlooks, Nueva York, New York University Press, 1995, pp. 491-521. 
trarse en temas como el cuerpo, la sexualidad, la reproducción y el cuestionamiento de la familia como institución central en la subyugación femenina. Eventualmente, estas discusiones se trasladan al campo jurídico, produciendo nuevos focos de regulación legal ${ }^{21}$.

La reformulación de lo político promueve, entonces, un renovado marco epistémico para comprender la incidencia de la cultura en las condiciones de desigualdad femenina. Lejos de reivindicarla como un precepto concordante con el orden de la naturaleza, desde los feminismos del siglo xx se empieza a promover una comprensión cultural, social y contingente de la igualdad, a fin de desentrañar, precisamente, el modo en que la "naturaleza femenina" es configurada en términos de inferioridad y sujeción. En esa configuración, el discurso jurídico aparece como una pieza central. A partir de esta advertencia, desde los primeros años del siglo XXI, las investigaciones jurídicas feministas se concentran en temas como la vinculación del discurso jurídico con la producción de subjetividades y en los relatos sobre el Derecho en la vida cotidiana.

La impugnación feminista a la neutralidad jurídica conlleva también considerables transformaciones en la enseñanza del Derecho. Julieta Lamaitre Ripoll califica estas transformaciones como "una revolución en las formas de la enseñanza del Derecho y de la escritura jurídica"22. Esa revolución se afirma desde "un rechazo a la posición objetiva y neutra del académico, y propone, en su lugar, incluir el valor de la experiencia personal como fuente de conocimiento sobre el Derecho"23.

La postulación de la neutralidad y objetividad del campo jurídico se vincula con el ingreso del Derecho a las filas del conocimiento científico, proceso que se inicia a fines del siglo XIX o principios del xx, según las distintas posiciones geopolíticas y las particularidades de

${ }^{21}$ Costa Wegsman, M., "Feminismos jurídicos en Argentina", en Bergallo, P. y Moreno, A. (eds.), Hacia politicas judiciales de género, Buenos Aires, Jusbaires Editorial, 2017, pp. 237-260.

${ }^{22}$ Lamaitre Ripoll, J., "E1 feminismo en la enseñanza del Derecho en Estados Unidos. Estrategias para América Latina", Academia. Revista sobre la enseñanza del Derecho de Buenos Aires, 6, 2005, pág. 177.

23 Ídem. 
cada sistema académico. El reconocimiento del Derecho en tanto disciplina científica dota a la flamante ciencia jurídica de mayor claridad y permeabilidad para el ingreso y ascenso en la carrera legal. En efecto, desde mediados del siglo $\mathrm{xx}$, se produce un marcado incremento de la matrícula femenina para el ingreso a la carrera académica legal, quebrando la tradicional homogénea composición varonil y blanca de los ámbitos del Derecho. Los efectos de ese quiebre repercuten aun hoy en las sucesivas y contundentes transformaciones no solo de los programas de estudio sino también de los modos de hacer Derecho en la enseñanza y las instituciones de justicia, tal como se puede corroborar en la profusa bibliografía y demás intervenciones feministas en el campo jurídico.

En ese sentido, se comprende la advertencia de la Profesora Ruiz Resa respecto de la primacía que se percibe en la economía del aprendizaje de los modelos del sistema del Common Law, más vinculados al ejercicio profesional en función de la actividad privada, sobre las profesiones jurídicas y la enseñanza del Derecho. En cambio, los sistemas del Derecho civil, fuertemente arraigados y comandados por las políticas del Estado-nación, forjan modelos educativos más vinculados con el hacer científico y el funcionariado. Desde esta advertencia, es necesario también considerar las diferencias de los sistemas de investigación y profesionalización académica, y sus criterios de evaluación y promoción, en términos sexogenéricos. En un estudio publicado este año, la League of European Research Universities (LERU) ${ }^{24}$ ofrece datos contundentes respecto de la incidencia negativa de los sesgos de género en las posiciones de las mujeres en las carreras profesionales académicas $^{25}$.

${ }^{24}$ League of European Research Universities (LERU), "Implicit bias in academia: A challenge to the meritocratic principle and to women's careers- And what to do about it", 23, 2018.

${ }^{25}$ Para un análisis de la subrepresentación femenina en los Tribunales del Derecho Internacional, ver: Grossman, N., "Sex on the Bench: Do Women Judges Matter to the Legitimacy of International Courts?", Chicago Journal of International Law, 12(2), 2012, pp. 647-684. 
En líneas generales, se corrobora allí que hay significativamente menos mujeres que varones en las posiciones más altas de todas las instancias de las instituciones académicas, la brecha salarial de género persiste y los trabajos de medio tiempo y los cargos precarizados son mucho más frecuentemente ocupados por mujeres que por varones. En suma, el estudio concluye que los procedimientos de evaluación académicos, si bien están supuestamente basados en criterios meritocráticos, son tendenciosos y desventajosos para las mujeres científicas. Esos sesgos se relacionan con presuposiciones respecto de la ciencia y el liderazgo, fuertemente enraizados en las culturas, y condicionan la distribución de los recursos académicos, incluido el reconocimiento profesional y la brecha salarial de género. Así, LERU señala la urgente obligación de las instituciones para actuar contra los sesgos de género en todos los niveles de las carreras académicas y fomentar, de esa manera, la convicción de que los sesgos suponen una violación del principio de meritocracia.

No obstante, desde el pensamiento feminista se han esgrimido diversas críticas respecto de las posibilidades de la meritocracia, criterio ligado a la neutralidad y objetividad científica. Sobre este punto, Lamaitre observa la particular falibilidad de la meritocracia en las facultades de Derecho. Afirma que tanto el acceso como el ascenso en las carreras legales, así como las posibilidades profesionales después de la graduación, dependen en gran medida de "el sexo, la raza y la clase social del estudiante (redes familiares, dinero, etc.)" ${ }^{\prime 26}$, elementos que se suman y condicionan el componente meritocrático. No obstante, "el discurso dominante, si bien reconoce las jerarquías, las vincula exclusivamente al mérito individual, y las acepta precisamente porque supuestamente son jerarquías de méritos, ignorando el elemento existente de privilegio de clase, sexo y raza" 27.

En definitiva, las críticas feministas advierten, desde posturas más optimistas, las limitaciones de los sistemas académicos para hacer frente a las desigualdades socioeconómicas y políticas en el acceso y

${ }^{26}$ Lamaitre, J., op. cit., pág. 183.

27 Ídem. 
la promoción de las estudiantes y profesionales del Derecho; y, desde posicionamientos más radicalizados, la complicidad de las instituciones del conocimiento en la reproducción y consolidación de esas desigualdades.

\section{Consideraciones finales}

En su análisis de las profesiones jurídicas en la economía del aprendizaje, la profesora Josefa Ruiz Resa parte de un postulado epistemológico-político en relación con el Derecho, su enseñanza, su aplicación y sus usos. Advierte así que la situación por ella presentada, analizada en profundidad y profusamente documentada en su texto, "no puede modificarse sólo desde la enseñanza del Derecho"28. Por el contrario, Ruiz Resa señala que la enseñanza del Derecho "se organiza y estructura para estar al servicio del orden político y social que lo crea", abonando a la idea de que la creación del Derecho se sustenta y alimenta de una serie de intereses y de conflictos, elementos constitutivos de toda organización político-social. En esa línea, la Prof. Ruiz Resa afirma que, en la actualidad, de las universidades se espera la formación de profesionales con talentos para "que pongan en marcha sus distintas competencias (...) según las demandas de su entorno laboral", en contraposición a objetivos políticos de otros tiempos, en los que la Universidad era llamada a generar "individuos humanistas" o "científicos críticos (Kant y Von Humboldt)" o "meros técnicos que se limitan a aplicar (...) la ley del Estado (Napoleón)" ${ }^{29}$. Desde la clave de lectura aquí propuesta, es imposible no advertir que tanto los modelos profesionales de la fase de la economía del aprendizaje, como los del Iluminismo o los del Derecho civil, están encuadrados en figuras masculinas blancas y europeas, grandes pensadores de la Historia -algunos de ellos-, anónimos servidores del capital -muchos otros-,

${ }^{29}$ Ver punto IV "La enseñanza del Derecho: hacia la formación de profesionales competentes" en Ruiz Resa, J., op. cit. 
cuyas ideas concurren para afianzar el androcentrismo eurocéntrico del Derecho. Como contraparte, las incidencias feministas en el campo jurídico confluyen en un heterogéneo cúmulo de ideas, cada vez más profuso, insoslayable para abonar a las alternativas contrapuestas a los requerimientos de la economía del aprendizaje. En tal sentido, resulta necesario y acaso urgente alimentar las genealogías feministas, articulando distintas tradiciones de la praxis jurídica, en la imaginación para crear nuevas narraciones (Olympe de Gouges), en la vindicación de los derechos consagrados (Mary Wollstonecraft) o en la reflexión sobre las reincidencias en la reconstrucción de nuevos sujetos del Derecho (Crenshaw, Davis, Spade).

La impugnación de la neutralidad jurídica, uno de los principios axiomáticos de los feminismos, tiene como contracara la advertencia de la condición política del Derecho. Ruiz Resa adhiere a estas premisas de las corrientes críticas del Derecho al señalar que el saber jurídico se construye y transforma desde diversos enclaves, tanto en la investigación jurídica académica como en la interpretación del Derecho que llevan a cabo no solo magistrados sino también el profesorado y el estudiantado jurídico en las aulas. No obstante, la Prof. Ruiz Resa advierte que esos aspectos del hacer jurídico son escasamente reconocidos tanto por las organizaciones internacionales que direccionan el saber jurídico en la línea de la economía del aprendizaje y "las autoridades políticas y académicas que han realizado las últimas reformas de los planes de estudios jurídicos" 30 , como también por quienes constituyen las amplias comunidades profesionales (magistradas/os, empleadas/os de las instituciones de justicia, profesorado y estudiantado del Derecho, comunidad científica en general). Esa falta de reconocimiento, concluye Ruiz Resa, socava las posibilidades de cuestionar las modalidades en las que actualmente se moldea el saber jurídico y, en cambio, resguarda la obediencia a las demandas de la economía del aprendizaje.

Consideramos que es, precisamente, en esas praxis marginadas donde se articulan discursos que abren la posibilidad de transformar 
el orden político-social y donde puede palparse un punto de fuga al desasosiego abrumador que genera el panorama del capitalismo global contemporáneo. Desde el movimiento feminista -organizado en la concepción del conocimiento como praxis, es decir, en la virtuosa intersección de debates, ideas y acciones diversas- el campo jurídico es intervenido para formular nuevas maneras de pensar y relacionarse con el Derecho.

Gran parte de la creación y de la transformación del Derecho se pone en juego en la apropiación, disposición y en las demandas de los movimientos sociales, en las proclamas por la extensión de los derechos, en la exigencia de su cumplimentación, en la puesta en práctica de derechos no reconocidos por la legalidad estatal pero socialmente legitimados, en los posicionamientos respecto de las decisiones judiciales, en la formulación de novedosos principios y mecanismos y, desde ya, en la creación de modos de la enseñanza, puntos de encuentro y canales de circulación alternativos de los materiales desconocidos o rechazados por los cánones institucionales. En efecto, la historia del Derecho moderno se formula al menos desde dos derroteros posibles, aquel que acompaña a los cánones tradicionales, legitimados por los tribunales, la academia y la institucionalidad estatal. Y otro camino, marcado por las luchas de quienes forman parte de la comunidad política desde una "inclusión diferencial" ${ }^{1}$, es decir, desde la desposesión, la marginación o, simplemente, la disconformidad, y que bogan por transformar radicalmente los discursos de la regulación legal.

${ }^{31}$ Mezzadra, S. y Neilson, B., La frontera como método, Madrid, Traficantes de Sueños, 2017. 
Formación jurídica y androcentrismo

\section{Bibliografía}

Costa Wegsman, M., "Introducción al dossier: Pensando E1 Derecho en Clave Pro-Fémina", Revista Electrónica. Instituto de Investigaciones Ambrosio L. Gioja, 19, 2017, pág. 2-11.

Costa Wegsman, M., "Feminismos jurídicos en Argentina", en Bergallo, P. y Moreno, A. (eds.), Hacia políticas judiciales de género, Buenos Aires, Jusbaires Editorial, 2017b, pág. 237-260.

De Beauvoir, S., El Segundo Sexo, Buenos Aires, Sudamericana, 2007.

Frug, M. J., "A postmodern legal manifesto", en Olsen, F., Feminist Legal Theory I: Foundations and Outlooks, Nueva York, New York University Press, 1995, pág. 491-521.

Grossman, N., "Sex on the Bench: Do Women Judges Matter to the Legitimacy of International Courts?", Chicago Journal of International Law, 12(2), 2012, pág. 647-684.

Heim, D., Mujeres y acceso a la justicia, Buenos Aires, Didot, 2016.

League of European Research Universities (LERU), "Implicit bias in academia: A challenge to the meritocratic principle and to women's careers- And what to do about it", 23, 2018.

Lamaitre Ripoll, J., "El feminismo en la enseñanza del Derecho en Estados Unidos. Estrategias para América Latina", Academia. Revista sobre la enseñanza del Derecho de Buenos Aires, 6, 2005, pág. 175-192.

Lipszyc, C., "Ciudadanía”, en Gamba, S. (ed.), Diccionario de estudios de género y feminismos, Buenos Aires, Biblos, 2007, pág. 58-62.

Marx, K., Sobre la cuestión judia, Buenos Aires, CS Ediciones, 1999.

Mezzadra, S. y Neilson, B., La frontera como método, Madrid, Traficantes de Sueños, 2017.

Olsen, F., "Feminism and Critical Legal Theory: An American Perspective", en Olsen, F. (ed.), Feminist Legal Theory I: Foundations and Outlooks, New York, New York University Press, 1995 pág. 473-485.

Pateman, C., El contrato sexual, Barcelona, Anthropos, 1995.

Ruiz Resa, J., "La enseñanza del derecho en la economía del aprendizaje", Revista Discusiones, Bahía Blanca, UNS, XIX, 2017. 
Smith, D. "Women's Perspective as Radical Critique of Sociology", en Fox Keller, E. y Longino, H. (eds.), Feminism \& Science, Oxford, Oxford University Press, 1996, pág. 27-38.

Scott, J. W., Las mujeres y los derechos del hombre: feminismo y sufragio en Francia, 1789-1944, Buenos Aires, Siglo Veintiuno Editores, 2002. 